\title{
Endoscopic Resection of a Giant Sinonasal Haemangiopericytoma with Preoperative Embolization and Cyanoacrylate Glue Injections: A Case Report and Literature Review
}

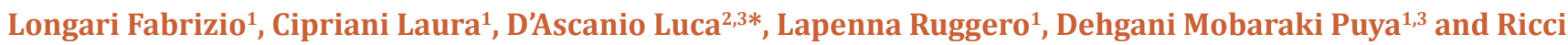 \\ Giampietro $^{1}$ \\ ${ }^{1}$ Department of Surgical and Biomedical Sciences, Section of Otorhinolaryngology, University of Perugia, Italy \\ ${ }^{2}$ Department of Otolaryngology - Head \& Neck Surgery, "Carlo Poma" Civil Hospital, Italy \\ ${ }^{3}$ Association "Naso Sano" Onlus, Umbria Regional Registry of Volunteer activities in Health System, Italy
}

Submission: May 13, 2017; Published: May 24, 2017

*Corresponding author: Luca D’Ascanio, Department of Otolaryngology - Head \& Neck Surgery, Carlo Poma, Civil Hospital, Strada Lago Paiolo 10 , 46100 Mantova, Italy, Tel: +39-3283186967; Fax: +39-075-5783574; Email: l.dascanio@gmail.com

\begin{abstract}
Background: Hemangiopericytomas (HPC) are rare mesenchymal tumors, which arise from the degeneration of Zimmerman's pericytes. They develop in the head and neck soft tissues in about $25 \%$ of cases and, in more than $50 \%$ of cases they involve the sinonasal region, especially the sphenoid sinus and ethmoidal labyrinth.

Methods: We report the case of a 71-year-old caucasian male, with a history of recurrent epistaxis followed by total nasal obstruction and anosmia. Radiographic and endoscopic examinations revealed a multilobed hypervascularized mass (49x 59x 49mm), occupying the nasal cavity and the paranasal sinuses. Pre-operative embolization, followed by intratumoral direct injections of cyanoacrylate glue, was carried out. A completely endoscopic resection was then performed.

Results: Post-operative histopatological and immunoistochemical examinations confirmed a sinonasal HPC. Endoscopic and radiological 2-year follow-up did not show any tumor recurrence.

Conclusion: Endoscopic intranasal excision under endoscopic guidance, with preceded by embolization and direct cyanoacrylate glue injections, is an effective treatment for sinonasal HPC.
\end{abstract}

Keywords: Tumors; Sinonasal haemangiopericitoma; Epistaxis; Endoscopic sinus surgery

\section{Introduction}

Even though vascular tumors are the most common mesenchymal malignancies of the head and neck soft region, haemangiopericytomas (HPCs) are extremely rare and occur in only $1 \%$ of cases [1]. Originally described by Stout and Murray in 1942, HPCs arise from the degeneration of the so-called «pericytes of Zimmermann». These cells, surrounding the basilar membrane and the endothelium of capillaries and venules, act as «mini» baroceptors modifying vessel diameter [2]. As a result of their vascular origin, HPCs are ubiquitous, with a more common skin, musculoskeletal, mediastinal, retroperitoneal and pelvic involvement. In about $25 \%$ of cases they develop in the head and neck soft tissues [3] and in more than 50\% of cases they involve the sinonasal region, especially the sphenoid sinus and ethmoidal labyrinth [4].

The etiology is still unknown: previous trauma or chronic corticosteroid therapy have been proposed, with no definite scientific confirmation [5]. The peak of incidence is between the sixth and seventh decade of life, with no significant prevalence of race or gender [6]. They have been reported as benign, malignant or borderline, because of their unpredictable clinical evolution: forms with low mitotic activity are reported to produce distant metastases in $15 \%$ of cases [7]. The mortality rate can reach 


\section{Global Journal of Otolaryngology}

50\% within 5-20 years after the first diagnosis [8]. The HPCs developing in the nasal and paranasal districts have some clinical, architectural and histopathological features that make them a separate entity (Sinonasal type haemangiopericytomas, SNTHPCs) [8]. SNTHPCs clinical presentation consists of nasal obstruction and epistaxis. More rarely, the tumor causes headache and/or ocular symptoms. We present the case of a giant SNTHPC endoscopically removed with prior embolization and intralesional injections of cyanoacrylate glue. A review of the literature on this topic is reported.

\section{Case Report}

A 71-year-old Caucasian man, with a previous history of intranasal polipectomy in 1986 and 1987, came in 2008 to our observation at the ENT Clinic of Perugia University (Italy) for recurrent epistaxis. Clinical and radiological examination (conventional angiography) showed a hyper vascular lesion. A surgical treatment was proposed to the patient. However, he refused such option. Two years later, he came back for a total nasal obstruction and anosmia. The anterior rhinoscopy showed an unique nasal cavity entirely occupied by a grayish-white bulky painless lesion, with a non-ulcerated and elastic surface. The mass did not show spontaneous or provoked bleeding and displayed a heartbeat synchronous pulse.

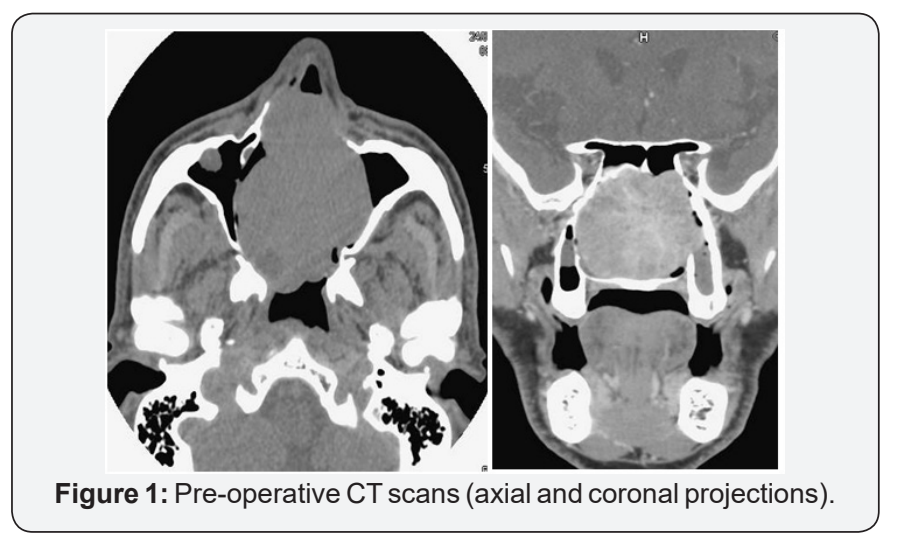

The control computed tomography with mean of contrast showed the hyper vascular fleshy mass with a volumetric increase ( $49 \times 59 \times 49 \mathrm{~mm}$ ) with respect to the previous exam. It had a multilobed aspect with the involvement of the whole nasal cavity, both ethmoidal labyrinths, both maxillary sinuses, the left frontal sinus and the sphenoid right one. The left lacrimal sac and the corresponding nasolacrimal duct appeared infiltrated, with a bilateral thinning of the lamina papyracea (Figure 1). A conventional angiography was performed to confirm the vascular nature of the tumor: a pathological flow from the branches of the internal maxillary artery and from the anterior and posterior ethmoidal arteries was noticed (Figure 2). A complete tumor embolization was performed with super selective catheterization of the internal maxillary artery with coaxial Rapid Transit $\AA$ system, using four vials of $10 \mathrm{ml}$ each of 500 micron microspheres. Np embolization of the ethmoidal arteries was carried out to avoid any risk of sight impairment.

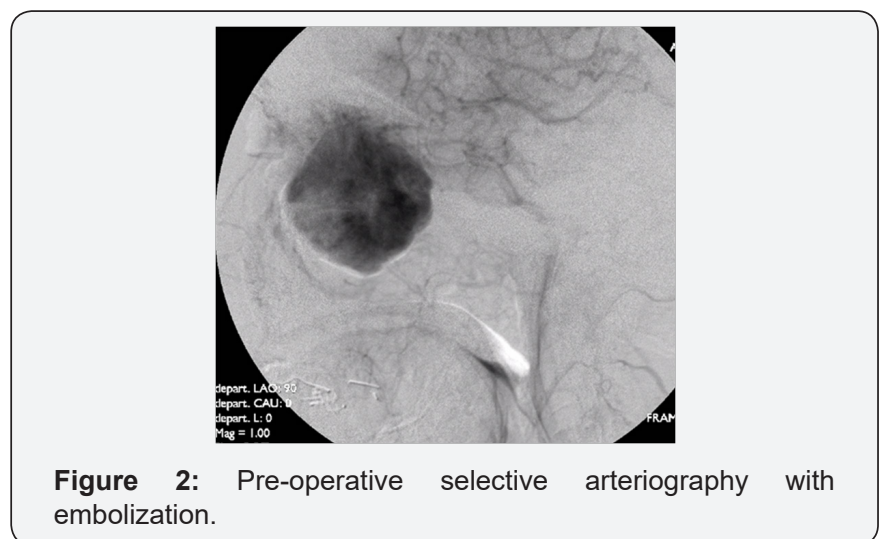

Immediately after the embolization and under general anesthesia, three direct intratumoral injections of cyanoacrylate glue were performed. A complete endoscopic resection was then carried out, using a four hands technique. The neoplasm was fully capsulated. The vascular pedicles were found coming from the right ethmoid and sphenopalatine region. After cauterization of the vascular pedicles, a complete excision of the tumor was performed with debrider. The underlying bone was drilled out and a frozen section analysis of soft tissue margins was performed to ensure complete surgical tumor resection. The bleeding was well controlled by cauterization, temporary packing and direct intra tumoral injections of Floseal ${ }^{\circledR}$ hemostatic matrix, without the need for blood transfusion. Then the nasal cavity was buffered with Surgicel ${ }^{\circ}$ and Merocel $₫$, which was removed after 5 days.
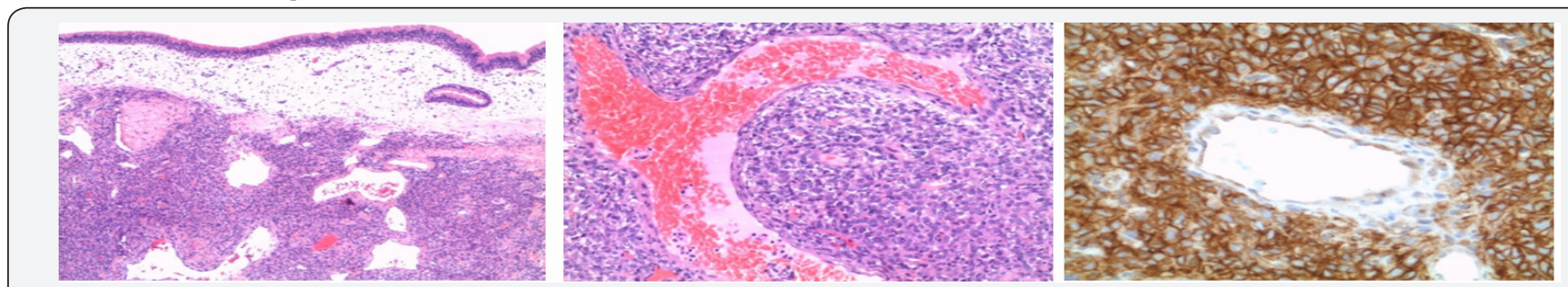

Figure 3: Histopathology of the lesion.

A: tumor showing a polypoid growth with respiratory epithelium cover. A richly vascular pattern consisting of large and small vessels lined by a single layer of flattened endothelial cells is shown (hematoxylin-eosin, original magnification 10x).

B: Mostly spindle or stellate tumor cells are arranged in short or whorled fascicles (hematoxylin-eosin, original magnification x400).

C: A diffuse and strong positivity for CD99 (x400). 


\section{Global Journal of Otolaryngology}
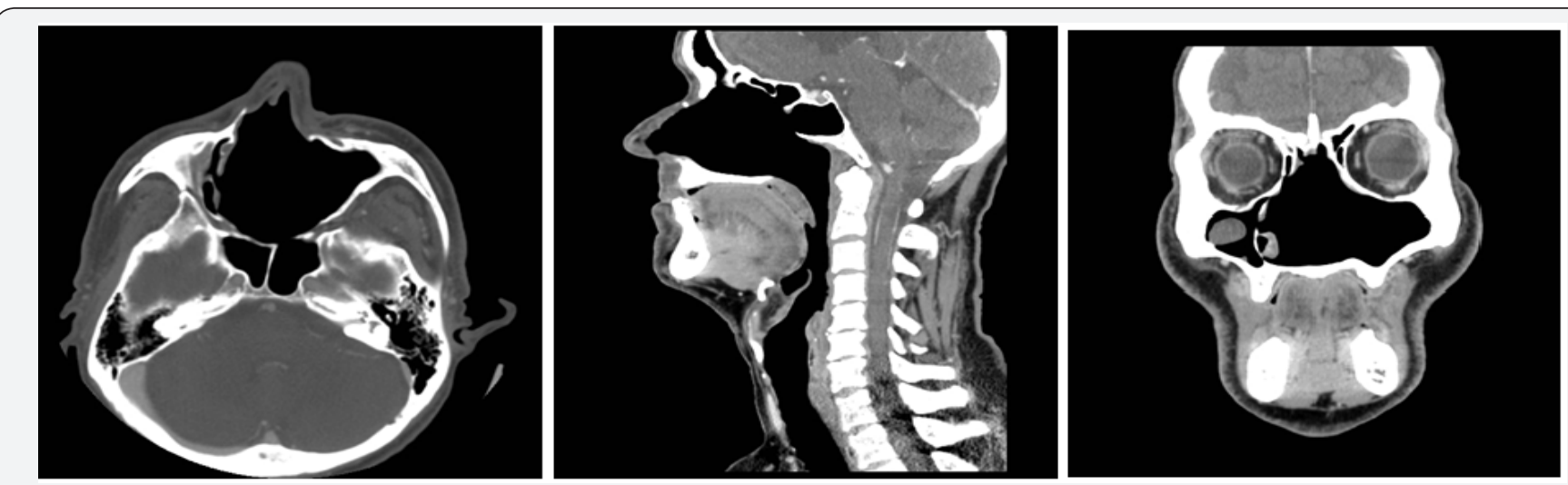

Figure 4: 48-month follow up CT-scans.

Post-operative histopatological examination showed spindle-shaped cells, with an indistinct cytoplasm and moderate nuclear atypia, placed around medium-sized and small vascular channels with a fine network of pericellular reticuline. They showed immunoistochemical positivity for CD99, BCL2, CD34, CD31 and smoth muscle actin, suggestive for a SNTHPC (Figure 3). The low mitotic index, the absence of necrotic areas or hemorrhage were predictive of a favorable behavior and adiuvant radiotherapy was not performed. The endoscopic and CT scan follow-up has not shown any tumor recurrence so far (Figure 4).

\section{Discussion}

SNTHPCs are rare mesenchymal tumors, that usually involve the nasal cavity and the ethmoid and sphenoid sinuses. These tumors can occur at any age, however, previous case series suggested a peak incidence during the sixth and seventh decades [6]. The presence of a persistent nasal obstruction associated with epistaxis is the typicl clinical presentation of SNHPCs [1]. Headache or compressive ocular findings of proptosis, epiphora and diplopia are rare, but can be found in case of extended tumor size or orbital extension. Racoussot reported a case of SNTHPC revealed by episodes of acute dacryocystitis [9]. The differential diagnosis from other more common pathologies of the sinonasal district (nasal polyposis, fungus ball, malignancies, encephalocele, etc.) should be made pre-operatively. Even though the final diagnosis is obtained only with histological examination, several authors suggest [1,10-12] avoiding biopsies, especially when the tumor size may cause severe bleeding [13]. However, misdiagnosis can lead to an incorrect surgical approach, with an incomplete excision, which may favor recurrences or metastases.

Pre-operative examinations must include neuroradiological investigation to detect the vascular nature of the tumor and its extension. CT scans of the nose and paranasal sinuses can demonstrate bone involvement, and the intravenous mean of contrast infusion can show tumor enahancement, but it does not allow a clear distinction with inflammatory fluid [14]. Usually, MRI scan shows a solid isointense mass, with a strong enhancement after gadolinium on T1 weighted sequences. On T2 weighted imaging, HPCs appear isointense to low intense, while inflammatory fluids have high-intense signals [12]. The best visualization of the vessel supply of the SNTHPC can be achieved by conventional digital angiography, which helps at the same time to plan a preoperative embolization [15].

Substantial intraoperative bleeding during SNTHPC surgical removal may be a major problem in the management of these highly vascularized tumors. Traditional preoperative embolization by a transarterial approach has proved beneficial but is often limited by the complex vascular anatomy and unfavorable location of such tumors. In our opinion, preoperative direct intralesional injections of cyanoacrylate are recommended, especially in case of extended SNHPCs to avoid severe bleedings and reduce surgical time. Traditionally the open approach (lateral rhinotomy) with or without pre-operative embolization, was the usual technique for the resection of large SNTHPCs [10].

Endoscopic procedures have been widely used in the last two decades, because of the avoidance of facial skin incision, the relatively short operation time, and the reduction of intraoperative bleeding. The use of endoscopic approach allows an excellent visualization of the operating field and a precise localization of the tumor origin even in case of anterior skull base involvement [11]. Direct local application of Floseal ${ }^{\circledR}$ is indicated during the surgical procedure as an adjunct to hemostasis when bleeding control by conventional procedures is insufficient. Floseal ${ }^{\circledR}$ hemostatic matrix is a combination of bovine-derived Gelatin Matrix and a human derived Thrombin Component largely employed in neuro-, cardiovascular and orthopedic surgery.

The histological and immunohistochemical features of the tumor are based on the presence of pleomorphic cells, with circular nuclei. They are surrounded by a reticular stroma and numerous vascular channels that typically exhibit a stag horn branching pattern. A strong immunoreactivity to smooth muscle actin is often detectable. Therefore, the pathological criteria for defining SNHPC malignancy are: tumor size, increased cellularity, cellular pleomorphism, increased mitotic activity, necrosis and hemorrhage [16]. Tumors with more than four mitoses per highpower microscopic field are defined as malignant [17]. A review 
of other Author's single case or series of SNHPCs of the last years has been done. The information obtained, particularly focused

on the type of treatment and follow-up outcomes are reported in Table 1.

Table 1: Review of the literature of outcomes in haemangiopericytoma treatment.

\begin{tabular}{|c|c|c|c|c|c|c|c|}
\hline Authors & Year & $\begin{array}{l}\text { Number of } \\
\text { cases }\end{array}$ & Embolization & Surgery & $\begin{array}{c}\text { Extra- } \\
\text { treatment }\end{array}$ & $\begin{array}{l}\text { Follow Up } \\
\text { (months) }\end{array}$ & Outcome \\
\hline Serrano [10] & 2002 & 5 & Yes & EES & No & $12-96$ & $\begin{array}{c}1 \mathrm{R} \\
4 \mathrm{NED}\end{array}$ \\
\hline Gillman [1] & 2004 & 1 & Yes & LR & No & 12 & NED \\
\hline Racoussot [9] & 2004 & 1 & No & EES & ART & 12 & NED \\
\hline Palacios [12] & 2005 & 7 & 1 Yes, 6 No & EES & 1 ART & $8-96$ & 1 R 6 NED \\
\hline Schlosser [18] & 2006 & 3 & 2Yes, 1 No & EES & No & 22 & NED \\
\hline I Hung [16] & 2006 & 1 & Yes & LR & No & 60 & NED \\
\hline Bignami [19] & 2010 & 10 & 1 Yes, 9 No & EES & No & 1to 138 & $\begin{array}{l}1 \text { DWD } \\
9 \text { NED }\end{array}$ \\
\hline Tessema [20] & 2012 & 12 & No & EES & No & $15-91$ & 12 NED \\
\hline Tojima [11] & 2012 & 1 & Yes & EES & No & 73 & NED \\
\hline
\end{tabular}

EES: Endonasal Endoscopic Surgery; LR: Lateral Rhinotomy; R: Recurrence; NED: Non Evidence of Desease; DWD: Died with disease; ART: Adiuvant Radiotherapy

\section{Conclusion}

SNTHPCs can be successfully managed endoscopically [1820]. A pre-operative embolization with superselective arterial catheterization should be done. Direct intralesional injection of acrylic glue is a feasible, safe, and effective technique for achieving presurgical devascularization, especially in case of extensive lesions with a complex vascularization. Intra-operative bleeding control can be successfully increased with local use of Floseal@ Hemostatic Matrix. Since SNTHPCs should be evaluated as a tumor with a malignant potential, intraoperative frozen sections study of surgical margins followed by the histological and immunohistochemical examination should guide complete tumor resection and the subsequent follow-up.

\section{Reference}

1. Gillman G, Pavlovich JB (2004) Sinonasal Haemangiopericytoma. Otolaryngol Head Neck Surg 131: 1012-1013.

2. Stout AP, Murray MR (1942) Haemangiopericytoma: a vascular tumor featuring Zimmerman's pericytes. Ann. Surg 116: 26-33.

3. Simon C, Toussaint B, Coffinet L (1997) Tumeurs malignes des cavites nasales et paranasales. Encycl Med Chir (Paris, France) Oto-rhinolaryngologie 20: 405-410.

4. Reiner SA, Siegel GJ, Clark KF, Lo KW (1990) Haemangiopericytoma of the nasal cavity. Rinology 28: 129-136.

5. Batsakis JG (1979) Tumors of head and neck. $2^{\text {nd }}$ edn. Wilkins and Wilkins, Baltimore, USA.

6. Thompson LD, Miettinen M, Wenig BM (2003) Sinonasal-type haemangiopericytoma: a clinicopathologic and immunophenotypic corporated of differentiation 104 cases showing perivascular myoid. Am J Surg Pathol 27: 737-734.

7. Carew JF, Singh B, Kraus DH (1999) Haemangiopericytoma of the head and neck. Laryngoscope 109(9): 1409-1411.

8. Lund VJ, Howard DJ (1996) Tumors of the paranasal sinuses. In Gershwin ME, Incudo GA, eds. Diseases of the sinuses Totowa, Humana Press, NJ, USA, 291-31.

9. Raccoussot F, Jourdel DP, Labalette Maetz B, Maurage CA, Darras J, et al. (2004) Hemangiopericytome des fosses nasales révélé par an episode de dacryocystite aigue. J Fr Ophtalmol 27(9): 1039-1042.

10. Serrano E, Coste J, Percodani A, Hervé S, Brugel L (2002) Endoscopic sinus surgery for sinonasal haemangiopericitoma. J Laryngol Otol 116: 951-954.

11. Tojima I, Ogawa T, Kouzaki H, Seno S, Shibayama M, et al. (2012) Endoscopic resection of malignant sinonasal tumors with or without chemotherapy and radiotherapy. J Laryngol Otol 126: 1027-1032.

12. Palacios E, Restrepo S, Mastrogiovanni L, Lorusso GD, Rojas R (2005) Sinonasal hemangiopericytomas: clinicopathologic and imaging findings. Ear Nose Throat J 84(2): 99-102.

13. Bhattachryya N, Shapiro NL, Metson R (1997) Endoscopic resection of a recurrent sinonasal hemangiopericytoma. Am J Otolaryngol 18(5): 341-344.

14. Mosesson RE, Som PM (1995) The radiographic evaluation of sinonasal tumors: an overview. Otolaryngologic Clinics of North America 28(6): 1097-1115.

15. Weber W, Henkes HK, Metz A, Berg-Dammer E, Kühne D (2001) Haemangiopericytoma of the nasal cavity. Neuroradiology 43(2): 183186. 
16. I Hung Lin, Fang Ying Kuo, Chih Ying Su, Hsin Ching Lin (2006) Sinonasal type hemangiopericytoma of the sphenoid sinus. Head and Neck Surgery 135(6): 977-979.

17. Enzinger FM, Smith BH (1976) Hemangiopericytoma: a review of 106 cases. Hum Pathol 7: 61-82.

18. Schlosser RJ, Woodworth BA, Gillespie MB, Day TA (2006) Endoscopic resection of sinonasal hemangiomas and hemangiopericytomas. ORL J

This work is licensed under Creative Commons Attribution 4.0 License

DOI:10.19080/GJ0.2017.08.555727
Otorhinolaryngol Relat Spec 68: 69-72.

19. Bignami M, Dallan I, Battaglia P, Lenzi R, Pistochini A, et al. (2010) Endoscopic, endonasal management of sinonasal haemangiopericytoma: 12-year experience. J Laryngol Otol 124(11): 1178-1182.

20. Tassema B, Anderson Eloy J, Folbe AJ, Ansted AS, Mirani NM, et al. (2012) Endoscopic management of sinonasal hemangiopericytoma.

\section{Your next submission with Juniper Publishers will reach you the below assets}

- Quality Editorial service

- Swift Peer Review

- Reprints availability

- E-prints Service

- Manuscript Podcast for convenient understanding

- Global attainment for your research

- Manuscript accessibility in different formats

( Pdf, E-pub, Full Text, Audio)

- Unceasing customer service

Track the below URL for one-step submission https://juniperpublishers.com/online-submission.php 